\title{
Relations between oral health and work ability among administrative workers
}

\author{
Rafael Aiello Bomfim¹, Edgard Crosato², Luiz Eugênio Nigro Mazzilli² \\ ${ }^{1}$ Universidade Federal do Mato Grosso do Sul - UFMS, School of Dentistry, Departament of Community Dentistry, Campo Grande, MS, Brazil \\ ${ }^{2}$ Universidade de São Paulo - USP, School of Dentistry, Departament of Community Dentistry, São Paulo, SP, Brazil
}

Received for publication: January 20, 2015 Accepted: March 16, 2015

Correspondence to: Rafael Aiello Bomfim

Cidade Universitária - FAODO/UFMS Av. Senador Fillinto Muller, s/n, Vila Ipiranga CEP 79080-190 - Campo Grande - MS - Brasil Phone: +55 1199991 0203, +55 6733457379 E-mail: rafael.aiello@ufms.br

\begin{abstract}
Aim: To analyze the relationships between perceived oral health quality of life and work ability index. Methods: The data regarding administrative workers of a private textile company in São Paulo - Brazil, included socio-demographic, occupational characteristics, self-perceived oral health (OHIP 14) and self-perceived work ability index (WAI). Results: The response rate of the questionnaires was $75.20 \%$ and the reliability of the instruments (Conbrach's alpha) was 0.89 for OHIP 14 and 0.64 for WAI. Linear multiple regression analyses showed that OHIP 14 was associated with educational level $(p=0.009)$ and work ability index $(p=0.001)$ of workers, regardless of other variables. Conclusions: These results showed the importance of adopting oral health programs in private companies to improve oral health and work ability.
\end{abstract}

Keywords: occupational dentistry; oral health; work capacity evaluation.

\section{Introduction}

Oral health status is a matter of great importance not only for individuals in terms of their quality of life $^{1}$ but also considering the demands and requirements related to occupational practice. In fact, anyone who experienced an oral disease knows how these situations affect the work ability leading to a dilemma: to work in unsatisfactory conditions (presenteism) or sick leave.

Since health related absenteeism rate is commonly used as an indicator of the health status of employees, some authors ${ }^{2-5}$ performed studies regarding oral diseases impacts on absenteeism and concluded that pulp pathologies (ICD-10, K04) and TMJ Dysfunction (ICD-10, K07.6) are usually its major causes. Despite its relevance, this information fails to evaluate the perception of social, physical and psychological disabilities and functional limitations in the work environment ${ }^{6}$, which suggests the use of other approaches and instruments to assess these impacts?

Among the classical quality of life instruments, were adopted the Work Ability Index (WAI), developed by the Finnish Institute of Occupational Health (FIOH) and the Oral Health Impact Profile-14 (OHIP-14). The WAI index is based on the assumption of a combination of human resources in relation to social, mental and physical demands, as well as its relationship to management, organizational culture, community and the workplace 8 . Its concept is expressed by the question "How well is, or will be, a worker in the present or near future, and how he will be able to perform his work according to the requirements of his status of health, physical and mental habilities?" This instrument has been validated for use in a Brazilian population ${ }^{10}$. The OHIP is a well-known instrument that also had been validated to Brazilian Portuguese and is used to record and to analyze the oral health 
impact profile. The 14-question version assesses seven dimensions: functional limitation; pain; physiologic discomfort, physical disability; physiologic disability; social disability and inability ${ }^{7}$.

The aims of this research were to assess and analyze the relationship between perceived oral health quality of life and the work ability among administrative workers of a private textile company in São Paulo, Brazil.

\section{Material and methods}

This study was conducted in the administrative department of a private company that had 134 employees at the time of the study. The research project was presented to the management and leadership to clarify the objectives and the ethical aspects involved.

The workers were informed about the research objectives and invited to participate. All the participants signed a free and informed consent form prior to participation.

The data collection (WAI and OHIP-14) was performed without any identification of the participant. Instructions for calculation of both are available in Tuomi et al. ${ }^{11}$ (2005) and in Oliveira and Nadanovsky ${ }^{7}$ (2005) respectively.

The dependent variable was the measurement of OHIP 14 as it represents the premise that oral health influences the work ability (better conditions of self-perceived oral health improve work ability index). The independent variables related to sociodemographics characteristics were sex, age, marital status, educational level and income. Independent variables related to occupational characteristics were job title, work shift, company affiliation time and job role. The work ability index (WAI) was also used to analyze relations between the variables.

The statistical analysis was conducted in STATA v.13 (Stata Corp., College St.,TX, USA). Kolmogorov-Smirnov test was performed to assess normality of OHIP 14 measurements. To analyze the correlation between OHIP 14 and other variables, the Spearman correlation coefficient was used. For comparison of the mean OHIP 14 with dichotomous qualitative variables without constant variance, the MannWhitney test was used. To compare means between qualitative variables with three or more categories, the Kruskal-Wallis test was used.

A multiple linear regression including variables with $p<0.05$ was performed followed by a residual analysis. The level of significance was $5 \%$.

The research project was approved by the Ethics Research Committee of the University of São Paulo School of Dentistry (approval protocol 181/2008), and the study followed all the ethical guidelines for human research.

\section{Results}

\section{Response rate}

Among all the employees only one did not participate as he was on sick leave; six were in external projects and six others were excluded since they participated in the "pretest" (applied for preliminary verification and prior analysis).
Of the remaining 121, 92 workers consented to participate. Only one participant failed to fill completely the questionnaires and was excluded. The response rate was $75.20 \%$.

\section{Questionnaires' reliability}

Internal reliability of the questionnaires was analyzed under Cronbach's alpha, with a confidence interval of $95 \%$. OHIP 14 score was 0.89 and WAI score 0.64, which showed good internal reliability.

\section{Demographic characteristics}

Of all participants $54.95 \%$ were male and $57.14 \%$ married or living with a partner and had complete university level $(78.02 \%)$. Mean age was 36.31 years $(\mathrm{SD}=9.6)$ ranging from 18 to 67 years old, shown in Table 1 .

Table 1 - Demographic Characteristics

\begin{tabular}{llll}
\hline Variables & & $\mathbf{n}$ & $\%$ \\
Sex & Male & 50 & 54.95 \\
& Female & 41 & 45.05 \\
\hline Marital status & Single & 33 & 36.26 \\
& Married/partner & 52 & 57.14 \\
& Divorced & 6 & 6.6 \\
\hline Educational Level & Elementary school & 1 & 1.1 \\
& Middle school & 1 & 1.1 \\
& High school & 18 & 19.78 \\
& University & 71 & 78.02 \\
\hline Age & Mean (SD) & Low & High \\
& 36.31(9.6) & 18 & 67 \\
\hline
\end{tabular}

\section{Functional characteristics}

All participants were full-time workers and their employment average time was 95.95 months $(\mathrm{SD}=77.5)$. The monthly salary ranged between US\$ 409 to 816 . Experts in textile area were $42.85 \%$ and $34.07 \%$ belonged to the administrative or engineering sectors.

\section{Characteristics of work ability}

Table 2 summarizes work ability characteristics. The average WAI score was 43.19 points (SD 4.44), ranging from 32 to 49 points. "Excellent" score met $54.95 \%$ of the participants.

\section{Descriptive analysis of oral health score}

The oral health score was 7.70 (SD 7.26) varying from 0 to 28 points on a scale that ranges from 0 to 56 points. As

Table 2 - Work Ability index (WAI)

\begin{tabular}{lll}
\hline WAI (points) & $\mathbf{n}$ & $\%$ \\
Lower (7-27) & 0 & 0 \\
Moderate (28-36) & 11 & 12.09 \\
Good (37-43) & 30 & 32.96 \\
Excellent (44-49) & 50 & 54.95 \\
\hline
\end{tabular}


Table 3 - Association score OHIP 14 with functional and Demographic Characteristics

\begin{tabular}{|c|c|c|c|c|}
\hline $\begin{array}{l}\text { Variables } \\
\text { Demographic }\end{array}$ & & $\mathrm{n}$ & mean (SD) & $\mathrm{p}$ \\
\hline \multirow[t]{2}{*}{ Sex } & Male & 50 & $5.72(7.34)$ & 0.01 \\
\hline & Female & 41 & $10.12(7.26)$ & \\
\hline \multirow[t]{2}{*}{ Marital status } & Not married & 39 & 8.25 ( 6.5 ) & 0.56 \\
\hline & Married/partner & 52 & $7.28(6.0)$ & \\
\hline \multirow[t]{2}{*}{ Educational level } & Not University & 20 & $10.05(9.5)$ & 0.004 \\
\hline & University & 71 & $6.53(4)$ & \\
\hline \multicolumn{5}{|l|}{ Functional } \\
\hline \multirow[t]{4}{*}{ Job title } & Administrative & 28 & $6.6(2.76)$ & 0.03 \\
\hline & Specialists & 39 & $5.79(1.05)$ & \\
\hline & Attendants & 19 & $10.92(1.55)$ & \\
\hline & Director & 5 & $7.15(1.41)$ & \\
\hline \multirow[t]{8}{*}{ Salary range (US\$) } & $<408$ & 2 & $6.5(3.5)$ & 0.67 \\
\hline & 409 to 816 & 23 & $9.69(1.75)$ & \\
\hline & 817 to 1224 & 20 & $8.05(1.78)$ & \\
\hline & 1225 to 1632 & 16 & $7(1.7)$ & \\
\hline & 1633 to 2040 & 13 & $8.69(1.96)$ & \\
\hline & 2041 to 2449 & 4 & $5.25(1.88)$ & \\
\hline & 2450 to 2857 & 2 & $1.5(0.5)$ & \\
\hline & 2858 or more & 11 & $5(1.65)$ & \\
\hline \multirow[t]{6}{*}{ Job role } & Administrative & 31 & 7.64(1.14) & 0.96 \\
\hline & Credit & 12 & $8.75(2.99)$ & \\
\hline & Human resources & 4 & $5(2.12)$ & \\
\hline & Accounts & 19 & $8.94(1.90)$ & \\
\hline & Sales & 16 & $6.93(1.67)$ & \\
\hline & Marketing & 9 & $6.44(1.95)$ & \\
\hline
\end{tabular}

this variable was not normally distributed $(\mathrm{p}<0.05$, Kolmogorov-Smirnov test) nonparametric tests were used to perform the statistical analysis. For OHIP 14 dimensions regarding problems in mouth or teeth in the past six months, were found the following results: functional limitation represented by speaking difficulty or deteriorated food taste was reported by $29.67 \%$ participants; pain in the mouth or teeth reported by $60.43 \%$; psychological discomfort represented by worry or stress was reported by $62.64 \%$; physical handicap like chewing limitation or having to interrupt meals was reported by $40.65 \%$; psychological disabilities like being ashamed or having trouble to relax reported by $48.35 \%$; social disabilities like being angry to others or difficulty to perform daily activities, reported by $36.26 \%$; limitations or disabilities like being unable to perform daily activities or felling that life in some way got worse because of oral or dental problems were reported by $25.27 \%$ of the participants.

\section{Analysis of factors associated with oral health}

Analysis didn't show significant differences between mean scores of OHIP 14 and age $(p=0.48)$ or marital status $(p=0.56)$. Significant differences regarding sex $(p=0.01)$ and educational level $(p=0.004)$ were observed. The results are shown in Table 3.
Although no significant associations were seen between OHIP-14 scores, work sector and salary range, associations were observed between OHIP-14 scores and job title variable, where specialists and attendants presented significant differences $(\mathrm{p}<0.05)$.

A significant correlation $(\mathrm{p}=0.0014)$ was observed between OHIP-14 scores and WAI. A multiple linear regression analysis including all variables was performed, age being considered as an adjustment variable. In this model the following variables showed significant associations for OHIP-14 score: WAI $(\mathrm{p}=0.0014)$, educational level $(p=0.009)$, sex $(p=0.133)$, job title $(p=0.863)$ and age $(\mathrm{p}=0.611)($ Table 3$)$.

After analysis it was realized that WAI and educational level had significant associations with oral health status, as shown in Table 4 . The squared adjusted coefficient $\left(\mathrm{r}^{2} \mathrm{a}\right)$ of 0.24 indicates that $24 \%$ of the variability of OHIP-14 could be explained by the variables that remained in the multivariate model. Analysis of the residues between the OHIP 14 (dependent variable) and the WAI score (independent variable) performed by D'Agostino-Pearson normality test, and the $\mathrm{p}$ value $(\mathrm{p}=0.44)$ showed that the residues belong to a normal curve, with the presence of some outliers (outliers). The conclusion is that the model is unbiased. 
Table 4 - Linear multiple regression analysis: OHIP 14 dependent variable

\begin{tabular}{llllll}
\hline Variables & $\mathbf{B}$ & $\mathrm{C}(95 \% \mathbf{B}$ & $\mathbf{R}$ & $\mathbf{r}^{2} \mathbf{a}$ & $\mathbf{p}$-valor \\
Work Ability index & -0.546 & $(-0.86 ;-0.22)$ & & & 0.001 \\
Educational level & -3.695 & $(-6.43 ;-0.95)$ & & & 0.009 \\
Job title & 0.148 & $(-1.55 ; 1.85)$ & 0.29 & 0.24 & 0.863 \\
Sex & 2.171 & $(-0.67 ; 5.02)$ & & & 0.133 \\
Age & 0.037 & $(-0.10 ; 0.18)$ & & & 0.611 \\
\hline
\end{tabular}

$\mathrm{p}$ model $=0.000 ;$ Standard error= 11.83 .

\section{Discussion}

The theoretical framework adopted in this research considers oral health, described by Locker ${ }^{6}$ (1988), as any limitation or loss of ability to perform daily activities. A good example is a person who does not pronounce the words correctly and, as a result, have problems in engaging in a conversation. The result is a limitation, characterized by adverse situations like experiencing problems at work due to its inability to communicate clearly ${ }^{6}$. These concepts emphasize qualitative differences in the experience of "social impact" as well as their characteristics. Individuals are more likely to have any social, physical and psychological disability if they experienced both pain and functional limitation. In addition, this pattern is part of the theoretical framework used to assess the work ability. This would result in job demands and resources of the individual to cope with them. If an individual's ability to meet these demands is reduced, it may be a stress trigger causing wear and consequently impairs working ability ${ }^{12}$.

This study evaluated the factors associated with oral health among administrative workers of a private textile company aiming to investigate its relationship to their quality of life ${ }^{1}$ and work ability. The analyzed questionnaires showed good reliability by Cronbach's alpha analysis ${ }^{13}$. OHIP 14 score showed internal reliability of 0.89 , a value above 0.7 , which is recommended ${ }^{13}$. The work ability index, as well as other studies ${ }^{14}$ showed a lower but acceptable reliability. The explanation is that there are issues with different weights in WAI, and when an issue is absent, the chance of changing the value of the overall score increases, generating a lower reliability. In OHIP-14 questionnaire, all questions have the same value, ranging from 1 to 4 points, so that an absent question does not change the overall value of the questionnaire, keeping its internal reliability.

While studies of absenteeism due to dental reasons are limited to ICD-10 information (diseases, causes), subjective tests with OHIP-14 instrument can identify physical, social and psychological disabilities, impairments or limitations. It could contribute to better elucidate the "social impact" of oral disorders ${ }^{15}$. Additionally, this approach allows identifying presenteeism ${ }^{2-5}$, in which despite of not being estranged from its labor activity, the employee's performance, safety and well being is reduced.

In this study, oral health was associated with sex $(p=0.01)$ and educational level $(p=0.004)$, and was not associated with age $(p=0.48)$ or economic status $(p=0.44)$, differently from Oliveira and Nadanovsky ${ }^{7}$ (2005) and
Robinson et al. ${ }^{16}$ (2001), who reported that OHIP-14 was inversely proportional related to age. A possible explanation may be the low age profile of the participants in the present study (mean 36.31 years old, SD 9.6 years). In close agreement with Sanders and Spencer ${ }^{17}$ (2004) and Oliveira and Nadanovsky $^{7}$ (2005) studies, sex and educational level relationships with oral health status were significant. While sex was dependent on work ability, educational level (with and without university grade) was independent of other variables, which is consistent with the findings of Sanders and Spencer ${ }^{17}$ (2004).

Job title was significantly associated with oral health status $(p=0.03)$ and was related to work ability and educational level, as seen on the analysis between the expert professionals and the attendant ones $(p<0.05)$. The explanation may be the different educational level between the groups, as expert workers were considered those who had university grade. Income (salary range) and job role variables did not show significant associations with oral health status, although the best oral health conditions were seen in those with higher educational level. These findings agree with those of Sanders and Spencer ${ }^{17}$ (2004). Work shift differences were not assessed as all participants worked full-time.

Oral health status may be affected not only by age but also as a consequence of work requirements and circumstances (i.e. chemical, or physical hazards). As a matter of fact both work requirements and oral health status may diminish the work ability, meaning the longer the worker is exposed to some circumstances, the more his work ability will be affected $^{10,14}$.

In the present research, multiple regression analysis confirmed oral health association with work ability. The squared adjusted coefficient $\left(r^{2} a\right)$ of 0.24 indicates that $24 \%$ of the variability of OHIP-14 could be explained by the variables that remained in the multivariate model, meaning that work ability and educational level were independently associated to other variables. This results agree with Guerra et al. ${ }^{18}$ (2014), who showed that $39 \%$ of OHIP-14 scores was explained by educational level $(p=0.03)$, age $(p=0.03)$, reason for visiting a dentist $(\mathrm{p}=0.01)$, oral health perception $(p<0.01)$ and satisfaction with teeth and mouth $(p<0.01)$. This result indicates that OHIP-14 can be useful for planning actions for oral health workers.

The prevalence of orofacial pain in the study of Lacerda et al. ${ }^{19}$ (2011) was $32.2 \%$, where the toothache was most frequent $(25.5 \%)$ and was the only one to have a high impact on workers in southern Santa Catarina state (Brazil), and this was associated with level education $(p=0.010)$, corroborating 
the present findings.

Given the results and limitations of this research and considering oral health a result of several interactions between people and working environment, some suggestions are presented:

\section{Promotion, protection and recovery of the oral health of workers}

Work ability was proven to be an independent factor statistically associated with oral health, which justifies actions related to the promotion, protection and recovery of workers' oral health. This evidence not only justifies, but also reinforces the importance of oral health practices as a regular component of occupational health programs in order to integrate surveillance actions. Oral health informative and educational procedures at workplace, as well as periodic exams are also of utmost importance not only to improve oral and general health and well being, but to integrate occupational activities and health care.

\section{New researches}

The cross-sectional design of this study does not support causal analysis between oral health and any of the tested independent variables. Given this limitation as well as the scarcity of studies assessing oral health at workplace, new studies are suggested (designed in a longitudinal way) to assess causal relations between oral health and those variables. The findings will be of great importance to evaluate the influence of oral health on general health status and to investigate work ability of different groups of workers in different occupational scenarios. Cohort studies, for example, can lead to a better understanding of the causal link between oral disease and occupational activity and how this affects the work ability.

\section{References}

1. Macedo CG, Queluz DP. Quality of life and self-perceived oral health among workers from a furniture industry. Braz J Oral Sci. 2011; 10: 226-32.

2. Santos EJ, Queluz DP. Factors involved in dentistry absenteeism since the foundation of the Labour Court from 1986 to 2008. Braz J Oral Sci. 2012; 11: 492-504.

3. Mazzili LEN, Crosato E. Analysis of sick leave due to dental reasons in municipal civil servants of São Paulo undergoing occupational expertise from 1996 to 2000. RPG Rev Pós Grad. 2005; 12: 444-53.

4. Bomfim RA, Mazzilli LEN, Michel-Crosato E, Camanho EDL, Crosato E. Absenteeism in Guarulhos municipal workforce due to oral and maxillofacial affections. J Manag Prim Health Care. 2013; 4: 169-75.

5. Togna GRD, Melani RHR, Crosato E, Michel-Crosato E, Biazevic, $M G H$. Use of the International Classification of Diseases in analysis of dental absenteeism. Rev Saúde Pública. 2011; 45: 512-8.

6. Locker D. Measuring oral health: a conceptual framework. Community Dent Health. 1988; 2: 3-18.

7. Oliveira BH, Nadanovsky P. Psychometric properties of the Brazilian version of the oral health impact profile- short form. Community Dent Oral Epidemiol. 2005; 33: 307-14.

8. IImarinen J. Aging and work. Occup Environ Med. 2001; 58: 546-51.

9. Martinez MC, Latorre MRD, Fisher FM. Work ability: literature review. Ciênc Saúde Col. 2010; 15(Suppl1): 1553-61.
10. Martinez MC, Latorre MRDO, Fisher FM. Validity and reliability of the Brazilian version of the work ability index. Rev Saúde Pública. 2009; 43: 525-32.

11. Tuomi K. Ilmarinen J, Jahkola A, Katajarinne L, Tulkki A, organizators. Work Ability Index. São Carlos: Edufscar; 2005.

12. IImarinen J, Tuomi K, Eskelinen L, Nygard CH, Huuhtanen P, Klockars M. Background and objectives of the Finnish research project on aging workers in municipal occupations. Scand J Work Environ Health. 1991; 17: 7-11.

13. Bland JMB; Altmann DG. Cronbach's Alpha. BMJ. 1997; 314: 572.

14. Martinez MC, Latorre MRDO. Health and work ability index for electricians in the state of São Paulo. Ciênc Saúde Col. 2008; 13: 1061-73.

15. Reisine $\mathrm{S}$. The impact of dental conditions on social functioning and the quality of life. Ann Rev Public Health. 1988; 9: 1-19.

16. Robinson PG, Gibson B, Khan FA, Birnbaum W. A comparision of OHIP14 and OIDP as interviews and questionnaires. Community Dent Health. 2001; 18: 144-9.

17. Sanders AE; Spencer AJ. Job characteristics and the subjective oral health of Australian Workers. Aust N J Public Health. 2004; 28: 259-66.

18. Guerra MJC, Greco RM, Leite ICG, Ferreira EF, Paula MVQ. Impact of oral health conditions in worker's quality of life. Ciência \& Saúde Coletiva 2014; 19: 4777-86.

19. Lacerda JT, Ribeiro JD, Ribeiro DM, Traebert J. Prevalence of orofacial pain and its impact on the oral health-related quality of life of textile industries workers of Laguna, SC, Brazil. Ciênc Saúde Col. 2011; 16: 4275-82. 